\section{Coronary stent deformation by a catheter-induced intramural haematoma}

A 71-year-old woman presented with chest pain on exertion. A coronary angiogram revealed a bifurcation lesion in the right coronary artery (figure 1A). A $2.75 \times 20 \mathrm{~mm}$ drug-eluting stent was deployed (figure 1B), and intravascular ultrasound showed that the stent was fully dilated (figure $1 \mathrm{C}$ ). However, a subsequent right coronary angiogram demonstrated severe coronary dissection from the ostium spreading to the stented segment (figure 1D), and a linear image of contrast can be seen outside the lumen underneath the proximal segment of the stent. Intravascular ultrasound demonstrated the presence of an intramural haematoma that had been caused by the dissection and deformed stent struts at the inlet of the stent, which were malapposed (figure 1E). Proximal to the stented segment, an even larger haematoma compressed the vessel lumen in a shape that was similar to the deformed stent (figure 1F) (see online supplementary video 1 ). We implanted a $3.5 \times 22 \mathrm{~mm}$ drugeluting stent in the proximal right coronary artery covering the entry point of the dissection, and inflated the non-compliant balloon in the deformed stent. The deformation was reshaped (figure $1 \mathrm{G}$ ) and the final angiogram (figure $1 \mathrm{H}$ ) showed residual dissection, but a good coronary flow.

An intramural haematoma is often managed with coronary stents ${ }^{1}$ because the progression of an intramural haematoma is not generally considered to be able to override the stent; however, the present case suggests that this hypothesis may not be suitable in some cases, and we should at least be aware of the possibility of stent deformation, which is caused by an intramural haematoma.

\section{Kenji Sadamatsu, Yoshibumi Antoku, Kensuke Ohe}

Department of Cardiology, St. Mary's Hospital, Kurume, Japan

Correspondence to Dr Kenji Sadamatsu, Department of Cardiology, St. Mary's Hospital, 422 Tsubukuhon-machi, Kurume, Fukuoka 830-8543, Japan;

k_sadamatsu@st-mary-med.or.jp

We declare that all authors listed meet the authorship criteria according to the latest guidelines of the International Committee of Medical Journal Editors, and all authors are in agreement with the manuscript.

Twitter Follow Kenji Sadamatsu at @k_sadamatsu

Contributors All authors identified and managed the case.

Competing interests None declared.

Patient consent Obtained.

Ethics approval St. Mary's Hospital.

Provenance and peer review Not commissioned; externally peer reviewed.

- Additional material is available. To view please visit the journal online (http://dx. doi.org/10.1136/heartasia-2016-010784).

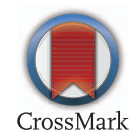

To cite Sadamatsu K, Antoku Y, Ohe K. Heart Asia 2016;8:24. doi:10.1136/ heartasia-2016-010784

Heart Asia 2016;8:24. doi:10.1136/heartasia-2016-010784

\section{REFERENCE}

1 Maehara A, Mintz GS, Bui AB, et al. Incidence, morphology, angiographic findings, and outcomes of intramural hematomas after percutaneous coronary interventions: an intravascular ultrasound study. Circulation 2002;105:2037-42.

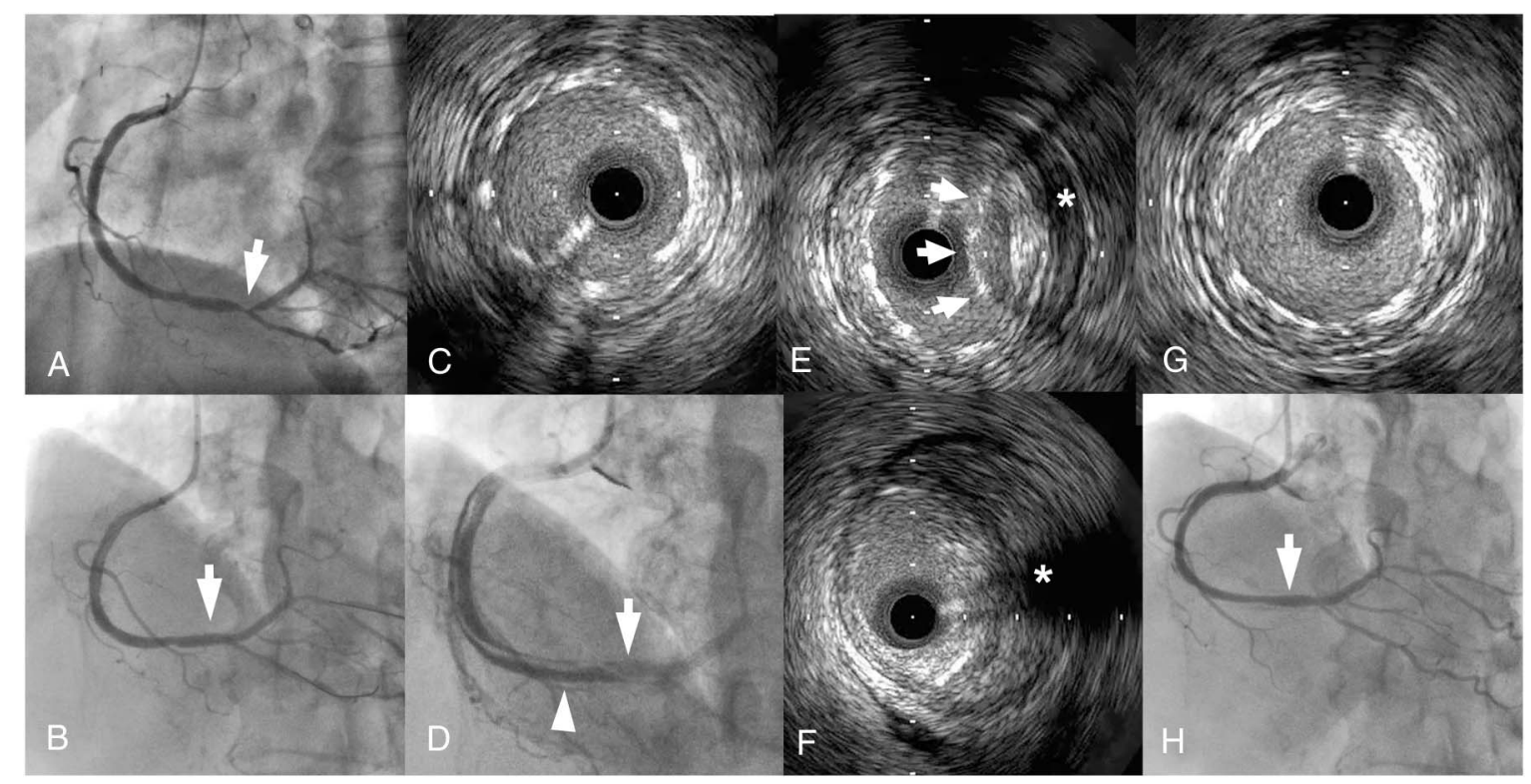

Figure 1 Serial findings of a right coronary angiogram and intravascular ultrasound. (A) A right coronary angiogram demonstrated a bifurcation lesion (arrow). (B) A drug-eluting stent was implanted in the lesion. (C) Intravascular ultrasound showed that the stent in the proximal segment (arrow in B) was fully dilated. (D) However, a subsequent angiogram revealed a long dissection from the ostium to the stented segment and poor opacification in the distal right coronary artery. (E) Intravascular ultrasound demonstrated the presence of deformed and malapposed (arrows) stent struts with an intramural haematoma caused by the dissection $\left(^{*}\right)$ at inlet of the stent (arrow in D), and (F) a similar-shaped vessel lumen compressed by an even larger haematoma $\left({ }^{*}\right)$ proximal to the stent (arrowhead in D) (see online supplementary video 1). After stenting to the ostium and re-dilation in the malapposed segment, the stent struts in the proximal segment (arrow in $\mathrm{H}$ ) were completely apposed (G), the coronary flow was improved $(\mathrm{H})$, although coronary dissection remained. 